\title{
Editorial Convidado
}

\author{
Implementação de OSCEs como Metodologia de Ensino e \\ Avaliação na NOVA Medical School (NMS) | Relato de um \\ Teste Piloto \\ Rita Viegas, MD*, Bruno Heleno, MD PhD**
}

O objetivo do ensino pré-graduado médico é conseguir, através da educação e do treino, a formação de profissionais competentes para o exercício de uma medicina segura.

O Oriented Structured Clinical Examination (OSCE) permite avaliar competências clínicas e, enquanto ferramenta de aprendizagem e de avaliação, tem vindo a ser reconhecido nos currículos médicos. ${ }^{1,2}$ O OSCE compreende um conjunto de estações nas quais os examinados desempenham tarefas clínicas, num período determinado de tempo, validadas por critérios objetivos e determinados para cada tarefa, resultando na demonstração de competências e atitudes. Esta ferramenta possibilita a avaliação da competência e, em simultâneo, orientar esta avaliação para a aprendizagem futura e para a construção de comportamentos e valores. Estes benefícios adicionais podem ser otimizados se for dado feedback imediato sobre o desempenho dos alunos, o qual incentiva à autorreflexão e à eventual modificação de comportamentos. ${ }^{3}$

Sabe-se que uma prática clínica segura advém da validação de competências clínicas no ensino pré-graduado e esta validação encontra-se dependente de um método apropriado de avaliação. ${ }^{1,2,4}$ Desta perspetiva, o feedback é fundamental para apoiar o desenvolvimento cognitivo e profissional, especialmente nas fases iniciais do currículo clínico. ${ }^{3}$

Quando o objetivo da avaliação é medir uma competência clínica, o OSCE é um método mais válido do que um teste puramente baseado no conhecimento. $^{2} \mathrm{O}$ conjunto de habilidades relevantes diferem à medida que avançamos no Mestrado Integrado de Medicina (MIM) e, apesar de serem limitadas no início, parece razoável integrar OSCEs nos estágios iniciais do currículo médico como um complemento à avaliação em outras áreas do conhecimento. ${ }^{2}$

Os docentes devem procurar, sempre, melhorar o desempenho dos alunos, incentivando-os à autorreflexão e fornecendo feedback, e, quando possível, os pacientes e o feedback dos colegas também deverão ser incluídos como

\footnotetext{
Assistente convidada da NMS, Unidade Curricular (UC) de Medicina Geral e Familiar (MGF), Assistente graduada de MGF, USF Cova da Piedade - ACES Almada Seixal

** Professor auxiliar da NMS | Faculdade de Ciências Médicas, USF das Conchas - ACES Lisboa Norte
} 
contributos para o processo de avaliação dos discentes. ${ }^{4,5} \mathrm{O}$ feedback recebido numa fase inicial dá aos alunos tempo para reagir e para adaptar as suas habilidades adequadamente ao seu processo de aprendizagem. ${ }^{3,4,5}$

\section{CONTEXTO LOCAL}

O plano de estudos da NOVA MS distribui-se ao longo de seis anos. Tem uma estrutura tipo Flexner, com o ciclo clínico a iniciar-se no $3^{\circ}$ ano e o sexto ano é um estágio profissionalizante. A MGF tem duas UC obrigatórias, uma no $5^{\circ}$ (semestral) e outra no $6^{\circ}$ ano (estágio parcelar de 4 semanas). No ano letivo de 2017/18 a UC de MGF da NMS considerou relevante fazer um teste piloto de um OSCE, ferramenta que ainda não havia sido implementada na NMS. 0 objetivo primordial foi repensar o ensino/avaliação dos alunos do $5^{\circ}$ e $6^{\circ}$ ano e, em simultâneo, estudar a viabilidade de implementar os OSCEs, enquanto metodologia de avaliação, para substituir o atual modelo em vigor para o $6^{\circ}$ ano (entrevista baseada num exercício escrito, crítico e descritivo das atividades desenvolvidas e observadas durante 0 estágio parcelar).

Fomos responsáveis pelo desenvolvimento, estruturação e realização deste projeto que decorreu em duas fases: 27 de abril de 2018 e 1 de junho de 2018.

\section{PREPARAÇÃO E IMPLEMENTAÇÃO DOS DOIS PILOTOS}

No caso da NMS a conceção e a implementação deste projeto piloto consistiu nas seguintes etapas: 6

\section{A: Preparação prévia}

1) Identificação dos líderes de projeto de entre a equipa de docentes do departamento: Rita Viegas (docente com particular interesse pela educação médica, em particular o ensino e avaliação de competências clínicas) e Bruno Heleno (professor da carreira docente universitária, que facilitou a articulação com as estruturas da faculdade). Os líderes definiram as tarefas, sequência de tarefas, atribuição de responsáveis. Os líderes estiveram envolvidos em toda a organização logística e no recrutamento de voluntários.

2) Brainstorm partilhado entre os elementos do departamento de MGF da NMS para determinar competências nucleares, transversais à prática segura de MGF, e a testar numa fase primordial. Deste trabalho resultou um consenso sobre seis competências transversais nucleares: 
anamnese, exame objetivo, entrevista motivacional, pedido de exames complementares de diagnóstico, prescrição farmacológica e comunicação interpares. Resultou, também, a identificação de seis conteúdos programáticos clínicos e nucleares: pessoa com multimorbilidade, pessoa com infeção aguda, adulto saudável com fatores de risco, pessoa com doença mental comum, grupos vulneráveis e pessoa com doença músculo-esquelética degenerativa. Estas áreas foram entendidas como relevantes para a formação dos alunos do $6^{\circ}$ ano do MIM, em termos de conhecimento e de aquisição de competências, e que deveriam ser atingidas pelos discentes no final da sua formação nesta UC.

3) Cronograma e especificação de tarefas para a concretização do projeto, nomeadamente:

- Clarificação de um objetivo específico, realista e com um prazo no tempo que foi comunicado a todos os docentes. Realizar dois pilotos no ano letivo de 2017-2018. Num dos pilotos teriam que ser avaliados cerca de 30 alunos.

4) Decisão sobre o número e duração das estações.

- Cada estação foi projetada para durar no máximo seis minutos, durante os quais se pode razoavelmente esperar que problemas de rotina sejam resolvidos.

- Cada circuito incluiu 7 estações de 6 minutos, com uma estação de descanso (6 minutos de desempenho +1 minuto de feedback +1 minuto de descanso entre estações). 0 número de estações foi determinado conjugando a matriz de conhecimentos e competências identificada no passo 2, a disponibilidade de recursos humanos (docentes e voluntários) e o número de estudantes esperados em cada turma de sexto ano.

5) Preparação de uma grelha de exame e de uma lista de estações. A grelha dos exames piloto resultou da integração da matriz de conhecimentos (passo 2) e competências e do número de estações (passo 4).

- A grelha de exame final consistiu em:

o Anamnese num doente com depressão (comunicação)

o Exame objetivo a um doente com infeção respiratória alta

o Entrevista motivacional a pessoa fumadora

o Revisão da terapêutica em pessoa com multimorbilidade

o Pedido de exames complementares de diagnóstico num doente com dor na anca de ritmo mecânico

- Anamnese e raciocínio diagnóstico em mulher grávida com hipertensão e proteinúria

o Escrita de uma carta de referenciação sobre mulher grávida com hipertensão e proteinúria. 
6) Definição da forma de classificação das estações.

- Dado ser uma primeira tentativa e porque haveria poucas oportunidades para treinar os avaliadores, optou-se por classificar os alunos através de uma grelha de comportamentos observáveis (checklist).

- Foi pedido aos avaliadores para fornecerem uma avaliação global de desempenho (não passou, passou em situação borderline, passou, passou muito bem e passou com excelência) e para identificarem, nalgumas estações, "bandeiras vermelhas" que significassem comportamentos que colocassem em perigo a vida dos doentes.

- Não foi pedida avaliação por parte do doente simulado.

- Não houve classificação formal dos alunos em nenhum dos pilotos.

7) Desenvolvimento das estações

- Criação e desenvolvimento das estações de acordo com a grelha de exame final.

o Foi pedido aos docentes-autor que escrevessem:

o Um guião para doente simulado

- Uma informação sumária do caso, para ser colocada à entrada da estação

- Uma grelha de comportamentos observáveis para a estação.

- Os autores foram instruídos para basear a informação para os as estações em cenários inerentes à sua prática clínica.

- Os autores foram instruídos a colocar um único comportamento observável por linha da grelha de comportamentos observáveis.

- Revisão das estações por pares

o Foi pedido a um docente, não envolvido na redação das estações, que lesse e comentasse os guiões e grelhas de comportamentos observáveis.

- Este foi um dos aspetos menos claros das instruções dos líderes de projeto para os outros membros da equipa. Isso levou a confusão de papéis e de tarefas a desempenhar. Para cumprir o cronograma, a revisão por pares foi feita essencialmente pelos líderes de projeto.

8) Compilação e organização logística:

- Espaço físico:

o No caso da NMS, foi decidido que seriam feitos 3-4 circuitos sequenciais ao longo de um dia. Existia na faculdade um espaço utilizado para ensino de competências clínicas, possível de ser transformado em 10 gabinetes médicos e uma sala de apoio. Dado que alguns desses gabinetes tinham material dificilmente amovivel, estavam 8 gabinetes disponíveis para utilização nos OSCE.

- Conceber a sinalização da estação e o fluxo do circuito de modo a garantir a sua acessibilidade, identificação e visibilidade. 
- Recursos humanos

o Contacto com tutores/docentes da UC e definição dos papéis a desempenhar por cada um.

- Avaliar e confirmar as disponibilidades para assegurar os circuitos dos dias 27 de Abril e 1 de Junho.

o Distribuição dos materiais de acordo com o papel a desempenhar (instruções para o candidato, instruções para o tutor treinado a desempenhar o papel de paciente simulado, instruções para o examinador).

- Economato e outros recursos

o Preparação das grelhas e materiais necessários (recursos materiais e recursos humanos).

o Elaboração de um mapa do circuito.

o Preparação da lista de alunos a avaliar.

\section{B: No dia do teste Piloto}

- Layout e marcação da estação

- Fixação do cenário na porta e tarefa

- Sinalização do fluxo no circuito

- Marcação e sinalização audível do tempo

- Confirmação dos materiais e equipamentos

- Preparação de bebida, comida e intervalos para os colaboradores

- Receção aos colaboradores e aos alunos (briefing inicial)

- Identificação do aluno e utilização de recurso que demonstre que estações foram percorridas

- Distribuição das listas de verificação aos examinadores e, no final, recolha das mesmas com preenchimento adequado

- Orientações finais (debriefing)

- Auscultação dos elementos submetidos ao teste piloto, em grupos, para validação e melhoria do processo.

\section{LIÇÕES RETIRADAS DOS PILOTOS}

\section{Fase 1}

A 27 de Abril foram avaliados 27 alunos do $5^{\circ}$ ano do MIM, que se encontravam a realizar o estágio parcelar de MGF do $5^{\circ}$ ano. Foram envolvidos seis dos dez docentes da UC de MGF e 29 médicos voluntários (entre especialistas e internos que colaboram com o ensino prático da UC de MGF e que fizeram de examinador, de paciente simulado ou de observador/suplente). Decorreram quatro circuitos durante o dia, dois de manhã e dois à tarde. 
O objetivo, neste primeiro piloto, de ter três elementos na sala, para além do examinando, prendia-se com a necessidade de aferir e validar o processo: o terceiro elemento poderia funcionar como suplente (em caso de falha de algum profissional no dia do circuito), observador externo do decorrer da estação e/ou segundo elemento para cotação da grelha.

No final do primeiro piloto foi solicitado aos intervenientes que expressassem a sua opinião em relação à experiência e aos circuitos (no momento do debriefing ou mesmo por mail, posteriormente, para evitar constrangimentos nesta participação):

- Os alunos participantes foram auscultados em grupos, moderados por uma docente afiliada da unidade de MGF. Os participantes salientaram a relevância clínica da prova de avaliação e o enfoque nas competências práticas. Referiram que a falta de experiência nesta metodologia de avaliação gerou ansiedade e desconforto face à exposição das suas competências numa prova deste tipo. Sentiram que o tempo disponibilizado para as tarefas era curto e muitos manifestaram que percebiam que esta prova avaliava aspetos diferentes dos que constam atualmente nos curricula médicos. Salientaram lacunas em relação ao seu atual conhecimento e desempenho de aptidões para o exercício da medicina geral e familiar, para esta UC específica.

- Os médicos voluntários mostraram grande interesse e envolvimento. Alguns tinham sido expostos a este tipo de avaliação enquanto alunos de outras escolas médicas portuguesas. A experiência foi positiva, nomeadamente quanto à relevância dos conteúdos. Referiram vários problemas com as grelhas de avaliação das estações e vários comentários sugerem-nos que o treino dos avaliadores foi insuficiente.

- O terceiro elemento foi uma mais valia porque permitiu a posterior comparação de resultados (na cotação da grelha de avaliação entre examinador e observador) e dar um feedback aos responsáveis pelo teste piloto, do decorrer de cada estação, com apontamento de pontos a alterar/melhorar.

\section{Fase 2}

No dia 1 de Junho decorreu o segundo teste piloto. Foram avaliados 12 internos, maioritariamente do $1^{\circ}$ e $2^{\circ}$ anos do internato de MGF, com o propósito de comparar o desempenho e a adequação das grelhas e das estações - era expectável que os internos da especialidade realizassem com facilidade qualquer uma das tarefas. Decorreram dois circuitos de manhã e para cada estação, contámos com a participação de dois médicos voluntários (um examinador e um paciente simulado). 
Nesta segunda simulação foram implementadas as melhorias resultantes do feedback dos alunos e dos médicos voluntários e docentes do Departamento da UC de MGF, nomeadamente em relação à aferição e simplificação das grelhas de avaliação, clareza dos objetivos para cada estação, acuidade no controlo do tempo e materiais disponíveis para o exercício. A maior dificuldade sentida foi o recrutamento de docentes/médicos voluntários/ médicos internos do $3^{\circ}$ e $4^{\circ}$ anos da especialidade de MGF para colaborarem também durante a tarde, mesmo prescindindo do elemento suplente.

No final do segundo piloto, foi também pedida uma avaliação dos participantes. Os elementos que participaram em ambas as simulações referiram melhoria do desempenho global relativamente a organização, clareza das grelhas e aplicabilidade das mesmas, clareza das instruções e conteúdos por estação, exequibilidade da tarefa para o tempo pretendido.

Este projeto piloto permitiu aos responsáveis e ao corpo docente da UC de MGF da NMS:

- Apreender sobre áreas de competência consideradas mais problemáticas para os alunos: elaboração de uma lista de diagnósticos diferenciais, dificuldade em estabelecer prioridades de gestão num doente com multimorbilidade.

- Proceder a modificações no ensino da UC de MGF ( $5^{\circ}$ ano).

- Concluir que será difícil assegurar a sustentabilidade dos OSCE sem haver um corpo de atores profissionais.

- Realizar uma análise SWOT (Strengths; Weaknesses; Opportunities; Threats)

\section{ANÁLISE SWOT - TESTE PILOTO OSCE}

\section{Pontos fortes:}

- Discussão entre os docentes da UC sobre os aspetos mais importantes do ensino em MGF e a incluir na matriz das estações dos OSCE

- Criação de uma matriz com os problemas de saúde mais comuns em cuidados de saúde primários e competências clínicas transversais (anamnese, exame físico, raciocínio diagnóstico, prescrição de tratamento, aconselhamento, comunicação interpares)

- Abrangência de conteúdos avaliados num único exame, de modo uniforme, replicável e objetivo

- Diminuição do viés na avaliação e validação de competências (em relação à avaliação tradicional)

- Avaliação em tempo real com possibilidade de feedback 


\section{Pontos fracos:}

- Número de estações e fiabilidade do circuito

- Tempo necessário para a preparação dos médicos voluntários envolvidos (treino de pacientes simulados, aplicação das grelhas de avaliação)

- Disponibilidade dos médicos voluntários e interferência com a atividade clínica dos mesmos

\section{Oportunidades:}

- Modificação de conteúdos e metodologia de ensino da UC do $5^{\circ}$ ano de MGF, já colocada em prática para o ano letivo 2018/19, após identificação de áreas de competência consideradas mais problemáticas para os alunos

- Treino de tutores, com envolvimento de internos da especialidade de MGF

- Contacto eventual para constituição de equipas de pacientes simulados (exemplo: escolas de teatro com envolvimento da junta de freguesia)

- Aumento do número de estações para possibilitar o aumento da fiabilidade do circuito

- Substituição, a longo prazo, do atual método de ensino/avaliação na UC de MGF com possível extensão a outras UC do MIM

- Parcerias com outras unidades curriculares no desenvolvimento e implementação de OSCE

- Contratação, pela NMS, de um professor com extensa experiência na implementação de OSCE

- Participação ativa e envolvimento dos membros da faculdade e do conselho pedagógico do MIM da NMS (modificação do ensino, conteúdos curriculares e da avaliação)

\section{Ameaças:}

- Tempo disponível

- Escassez de avaliadores remunerados

- A ausência de um grupo de pacientes simulados/grupo de atores profissionais dificulta a sustentabilidade dos OSCE

- Dificuldade em assegurar a sustentabilidade dos OSCE sem recurso a tutores clínicos, internos da especialidade ou uma combinação dos dois, agravada nos meses dedicados à avaliação dos próprios internos (janeiro a março).

- Custo do exame

- Necessidade de mais espaços físicos, para o caso de ser necessário implementar circuitos paralelos

- Aceitação da mudança do paradigma atual de ensino/avaliação para o modelo OSCE pelos discentes e docentes

- Ausência de reconhecimento institucional do volume de trabalho envolvido no desenvolvimento e manutenção dos OSCE 


\section{CONCLUSÃO}

Este projeto piloto permitiu demonstrar que os OSCE podem ser implementados na NMS. A principal ameaça ao projeto prende-se com a dificuldade em recrutar avaliadores e doentes simulados para mais que um OSCE por ano. Apesar da complexidade inerente à sua implementação acreditamos que a validação desta ferramenta de ensino/ avaliação será possível com o envolvimento da Direção da Faculdade, do Departamento de Educação Médica e do corpo docente das várias UC do MIM. A participação ativa e os contributos do corpo docente, a partilha de experiências e conhecimentos com faculdades que já implementaram esta metodologia, a aferição deste processo e a sua respetiva validação serão propulsores à mudança de mentalidade necessária à modificação do ensino/ aprendizagem na NMS.

\section{Referências Bibliográficas}

1. AVALIAÇÃO DE COMPETÊNCIAS ATRAVÉS DE OSCE. Essências EDUcare. Novembro de 2009. Gabinete de Educação Médica da FMUC. Disponivel em https:// www.uc.pt/fmuc/gabineteeducacaomedica/fichaspedagogicas/Essencias13

2. MadalenaFolque Patrício, MiguelJulião, Filipa Fareleira\&António VazCarneiro(2013) Is the OSCE a feasible tool to assess competencies in undergraduate medical education? Medical Teacher, 35:6, 503-514, DOI: 10.3109/0142159X.2013.774330

3. Zaric, S., \& Belfield, L. A. (2015). Objective Structured Clinical Examination (OSCE) with Immediate Feedback in Early (Preclinical) Stages of the Dental Curriculum. Creative Education, 6, 585-593. http://dx.doi.org/10.4236/ce.2015.66058

4. Gormley G. (2011). Summative OSCEs in undergraduate medical education. The Ulster medical journal, 80(3), 127-132. Disponível em https://www.ncbi.nlm. nih.gov/pubmed/23526843

5. Casey, Petra M. et al. To the point: reviews in medical education-the Objective Structured Clinical Examination. American Journal of Obstetrics \& Gynecology, Volume 200, Issue 1, 25-34.DOI: https://doi.org/10.1016/j.ajog.2008.09.878

6. Implementing an OSCE. In Harden R, Lilley P, Patrício M. The Definitive Guide to the OSCE. The Objective Structured Clinical Examination as a performance assessment. $1^{\text {st }}$ Edition. Churchill Livingstone: 2015. P.115-126. 